\title{
Rationale, study design, and analysis plan of the Alveolar Recruitment for ARDS Trial (ART): Study protocol for a randomized controlled trial
}

The ART Investigators

\begin{abstract}
Background: Acute respiratory distress syndrome (ARDS) is associated with high in-hospital mortality. Alveolar recruitment followed by ventilation at optimal titrated PEEP may reduce ventilator-induced lung injury and improve oxygenation in patients with ARDS, but the effects on mortality and other clinical outcomes remain unknown. This article reports the rationale, study design, and analysis plan of the Alveolar Recruitment for ARDS Trial (ART).

Methods/Design: ART is a pragmatic, multicenter, randomized (concealed), controlled trial, which aims to determine if maximum stepwise alveolar recruitment associated with PEEP titration is able to increase 28-day survival in patients with ARDS compared to conventional treatment (ARDSNet strategy). We will enroll adult patients with ARDS of less than $72 \mathrm{~h}$ duration. The intervention group will receive an alveolar recruitment maneuver, with stepwise increases of PEEP achieving $45 \mathrm{cmH}_{2} \mathrm{O}$ and peak pressure of $60 \mathrm{cmH}_{2} \mathrm{O}$, followed by ventilation with optimal PEEP titrated according to the static compliance of the respiratory system. In the control group, mechanical ventilation will follow a conventional protocol (ARDSNet). In both groups, we will use controlled volume mode with low tidal volumes ( 4 to $6 \mathrm{~mL} / \mathrm{kg}$ of predicted body weight) and targeting plateau pressure $\leq 30$ $\mathrm{CmH}_{2} \mathrm{O}$. The primary outcome is 28-day survival, and the secondary outcomes are: length of ICU stay; length of hospital stay; pneumothorax requiring chest tube during first 7 days; barotrauma during first 7 days; mechanical ventilation-free days from days 1 to 28; ICU, in-hospital, and 6-month survival. ART is an event-guided trial planned to last until 520 events (deaths within 28 days) are observed. These events allow detection of a hazard ratio of 0.75 , with $90 \%$ power and two-tailed type I error of 5\%. All analysis will follow the intention-to-treat principle.

Discussion: If the ART strategy with maximum recruitment and PEEP titration improves 28-day survival, this will represent a notable advance to the care of ARDS patients. Conversely, if the ART strategy is similar or inferior to the current evidence-based strategy (ARDSNet), this should also change current practice as many institutions routinely employ recruitment maneuvers and set PEEP levels according to some titration method.
\end{abstract}

Trial registration: ClinicalTrials.gov Identifier: NCT01374022

Keywords: Acute respiratory distress syndrome, Alveolar recruitment, PEEP, Mechanical ventilation, Clinical trials, Randomized

\footnotetext{
* Correspondence:

Research Institute - Hospital do Coração (IEP- HCor), Rua Abílio Soares 250,

12th floor, CEP: 04005-000, São Paulo, SP, Brazil
} 


\section{Background}

Acute respiratory distress syndrome (ARDS) is a common problem in critically-ill patients, associated with inhospital mortality between $41 \%$ and $58 \%$ [1-3] and reduced quality of life among survivors $[4,5]$. Although mechanical ventilation provides essential life support, it can worsen lung injury [6]. Mechanisms of ventilatorinduced lung injury include regional alveolar overdistention, repetitive alveolar collapse with shearing (atelectrauma), and oxygen toxicity $[7,8]$.

Ventilation with low tidal volumes $(\leq 6 \mathrm{~mL} / \mathrm{kg})$ and targeting plateau pressures of $30 \mathrm{cmH}_{2} \mathrm{O}$ or less improves survival compared to the use of high volumes $(12 \mathrm{~mL} / \mathrm{kg})$, confirming the relevance of avoiding overdistention in ARDS [9]. Although this strategy improved care of ARDS patients, mortality is still unacceptably high [3]. Experimental data suggest that atelectrauma is prominent in ARDS $[10,11]$ and may be a contributor to ARDS mortality [12]. Opening of collapsed lung tissue by recruitment maneuvers and preventing further collapse by using titration of PEEP may prevent atelectrauma. Maximum alveolar recruitment followed by PEEP titration is a relatively simple and widely available intervention.

Some studies demonstrated that maximum recruitment strategy, achieving PEEP of $45 \mathrm{cmH}_{2} \mathrm{O}$ and peak pressure of $60 \mathrm{cmH}_{2} \mathrm{O}$, can fully recruit the lung and reverse hypoxemia in most ARDS patients, without major adverse events $[13,14]$. However, a systematic review of alveolar recruitment maneuvers found only four randomized trials and was inconclusive regarding the effect of recruitment maneuvers on survival and other patients' relevant outcomes [15]. Recently a pilot study randomized 20 patients to an alveolar recruitment maneuver with progressive PEEP elevation up to $40 \mathrm{cmH}_{2} \mathrm{O}$ and peak pressure of $55 \mathrm{cmH}_{2} \mathrm{O}$ plus PEEP titrated according to peripheral oxygen saturation or to ARDSNet strategy [16]. There were a decrease in some systemic cytokines, and improvement in oxygenation and compliance. As expected, the trial was not powered to and did not show any difference in mortality and other clinical outcomes. Therefore, a trial with high methodological quality and power to assess whether maximum alveolar recruitment followed by ventilation with titrated PEEP improves clinical outcomes in ARDS patients is highly needed.

\section{Methods}

\section{Objectives}

Our primary objective is to determine if maximum alveolar recruitment associated with PEEP titrated according to the static compliance of the respiratory system (ART strategy) increases 28-day survival rate of patients with acute respiratory distress syndrome compared to conventional treatment (ARDSNet strategy).
Secondary objectives are to evaluate the effect of the ART strategy compared to ARDSNet strategy on the following outcomes: length of hospitalization; pneumothorax requiring chest tube at 7 days; barotrauma (any pneumothorax, pneumomediastinum, subcutaneous emphysema or pneumatocele $>2 \mathrm{~cm}$ after randomization) at 7 days; ventilator-free days from days 1 to 28; intensive care unit, in-hospital, and 6-month survival.

\section{Study design}

ART is a randomized, stratified, multicenter trial with allocation concealment and intention-to-treat analysis. Patients with ARDS will be treated with a stepwise maximum alveolar recruitment maneuver followed by ventilation with optimal PEEP (ART Strategy) vs. a conventional approach (ARDSNet Strategy). This is an event-guided trial which will end when 520 events (deaths within 28 days) are observed. Patients will be followed up to 6 months, although the main outcome is determined at the 28-day follow-up.

\section{Screening}

Eligibility will be evaluated in two phases: screening phase and defining eligibility phase.

In the screening phase, patients will be considered for inclusion in the study if they are receiving invasive mechanical ventilation and have ARDS of less than $72 \mathrm{~h}$ duration. All of the following criteria should be met [17]: acute onset respiratory failure; bilateral pulmonary infiltrate on chest X-ray compatible with pulmonary edema; severe hypoxemia, defined as $\mathrm{PaO}_{2} / \mathrm{FiO}_{2} \leq 200$ in arterial blood gases for less than $72 \mathrm{~h}$; absence of left atrial hypertension based on the medical team's evaluation (clinical or echocardiographic signs); and presence of a risk factor for lung injury.

The following are exclusion criteria (exclusion if any one present): age $<18$ years; use of vasoconstrictor drugs in increasing doses over the past $2 \mathrm{~h}$ (norepinephrine increase $\geq 0,5 \mathrm{mcg} / \mathrm{kg} / \mathrm{min}$ or dopamine increase $\geq 5 \mathrm{mcg} / \mathrm{kg} / \mathrm{min}$ ) or mean arterial pressure $<65 \mathrm{mmHg}$; this may be a transient criterion, since patients meeting this criterion might be included later if hemodynamics improves; contraindications to hypercapnia such as intracranial hypertension or acute coronary syndrome; and undrained pneumothorax or subcutaneous emphysema.

While waiting for the consent of a legal representative or for at least $3 \mathrm{~h}$, we suggest to ventilate patients using a conventional approach as follows [9]: volume-controlled mode, tidal volume of 4 to $6 \mathrm{~mL} / \mathrm{kg}$ of predicted body weight to ensure plateau pressure $\leq 30 \mathrm{cmH}_{2} \mathrm{O}$, PEEP, and $\mathrm{FiO}_{2}$ adjusted according to the ARDSNet table (Table 1) to maintain $\mathrm{SpO}_{2} \geq 88 \%$ and $\mathrm{PaO}_{2} \geq 55 \mathrm{mmHg}$, flow of $60 \mathrm{~L} / \mathrm{min}$, descending waveform, inspiratory pause of $0.5 \mathrm{~s}$, inspiratory to expiratory ratio (I:E) of $1: 1$ to $1: 2$, 
Table 1 ARDSNet table of $\mathrm{FiO}_{2}$ and PEEP values to keep $\mathrm{SpO}_{\mathbf{2}} \geq \mathbf{8 8} \%$ or $\mathrm{PaO}_{\mathbf{2}} \geq \mathbf{5 5} \mathbf{m m H g}$

\begin{tabular}{|c|c|c|c|c|c|c|c|c|c|c|c|c|c|c|}
\hline $\mathrm{FiO}_{2}$ & $30 \%$ & $40 \%$ & $40 \%$ & $50 \%$ & $50 \%$ & $60 \%$ & $70 \%$ & $70 \%$ & $70 \%$ & $80 \%$ & $90 \%$ & $90 \%$ & $90 \%$ & $100 \%$ \\
\hline PEEP & 5 & 5 & 8 & 8 & 10 & 10 & 10 & 12 & 14 & 14 & 14 & 16 & 18 & $18-24$ \\
\hline
\end{tabular}

respiratory rate to keep $\mathrm{PaCO}_{2}$ between 35 and $60 \mathrm{mmHg}$. Alveolar recruitment maneuvers should be avoided.

Predicted body weight should be calculated for all patients according to the formula:

$$
\begin{aligned}
& \begin{array}{l}
\text { Men : Predicted body weight }(\mathrm{kg}) \\
\quad=50+2.3((\text { height }[\mathrm{cm}] * 0.394)-60)
\end{array} \\
& \begin{array}{l}
\text { Women : Predicted body weight }(\mathrm{kg}) \\
\quad=45.5+2.3((\text { height }[\mathrm{cm}] * 0.394)-60)
\end{array}
\end{aligned}
$$

\section{Defining eligibility}

Right after obtaining informed consent, ventilator will be set as described above (if the recommended ventilation were not set yet) and $\mathrm{FiO}_{2}$ will be adjusted to $100 \%$ and PEEP to $10 \mathrm{cmH}_{2} \mathrm{O}$ (except if previous PEEP were $\geq 16$ $\mathrm{cmH}_{2} \mathrm{O}$; in this case PEEP will be maintained). Arterial blood gases will be measured after $30 \mathrm{~min}$.

Patients will be considered eligible if the $\mathrm{PaO}_{2}$ measured with $\mathrm{FiO}_{2}=100 \%$ and PEEP $=10 \mathrm{cmH}_{2} \mathrm{O}\left(\right.$ or $\geq 16 \mathrm{cmH}_{2} \mathrm{O}$ ) is $200 \mathrm{mmHg}$ or less, and less than $72 \mathrm{~h}$ have been spent since the first time a $\mathrm{PaO}_{2} / \mathrm{FiO}_{2} \leq 200$ was determined.

\section{Criteria for withdrawal of patients from the trial}

The withdrawal of a patient from the study will occur only if consent is withdrawn by the patient, his/her legal representative, or the patient's primary care physician.

Treatment should be discontinued if the patient is sufficiently unstable to contraindicate the continued use of high PEEP levels. The necessary measures to minimize instability and adverse effects caused by the use of high PEEP levels should be implemented as deemed appropriate by the medical team. However, patient follow-up will proceed normally, that is, the patient will not be excluded from follow-up and analyses.

\section{Randomization and allocation concealment}

Patients will be randomized in a 1:1 ratio to the ART strategy or the ARDSNet strategy.

The random allocation list was generated in blocks (number of treatments per block will be kept confidential to avoid prediction of future patients' allocation) and was stratified by investigator center age, and $\mathrm{PaO}_{2} / \mathrm{FiO}_{2}$ ratio $(\leq 100$ or $>100)$. Allocation concealment will be maintained by means of a web-based central, automated randomization system, available $24 \mathrm{~h}$ a day (ACT-Clinic), developed by a team of programmers and investigators from the Research Institute at Hospital do Coração (IEP-HCor). The group to which the patient will be allocated will only be disclosed after patient enrollment information is recorded in the electronic system. This prevents the investigator and the medical team from predicting to which treatment group the patient will be allocated. To include a patient in the study, investigators must simply access the IEP-HCor website (https://servicos.hcor.com.br/ iep/estudoclinico), log in with individual username and password, and fill in a short medical record form.

\section{Interventions}

Table 2 summarizes the procedures that will be used for ART and ARDSNet groups in this study.

\section{ART strategy (maximum alveolar recruitment maneuver plus PEEP titration)}

If patients are assigned to the ART strategy, the following steps should be observed (Figure 1):

1. Preparation for the recruitment maneuver Patients will be sedated, paralyzed (with a neuromuscular blocker), and kept in supine position. Closed endotracheal suction system will be installed. Monitoring will be provided with at least: heart rate, cardiac rhythm, periferic oxygen saturation, and blood pressure (preferably invasive method). Hypovolemia will be corrected by crystalloid or colloid infusion until variation of arterial pulse pressure $\leq 13 \%$, or central venous pressure of $>10$ $\mathrm{cmH}_{2} \mathrm{O}$ if variation of arterial pulse pressure measurement is not available. If the variation of arterial pulse pressure method is used, we recommend to transiently setting tidal volume to $8 \mathrm{~mL} / \mathrm{kg}$ for $15 \mathrm{~min}$ before measurements

2. Maximum alveolar recruitment maneuver Mechanical ventilator will be set to pressurecontrolled mode with $\mathrm{FiO}_{2}$ of $100 \%$; respiratory rate of $10 / \mathrm{min}$ and I:E ratio of $1: 1$. Alveolar recruitment maneuver steps are described below:

- Recruitment starts with PEEP of $25 \mathrm{cmH}_{2} \mathrm{O}$ and driving pressure of $15 \mathrm{cmH}_{2} \mathrm{O}$. These parameters will be maintained for $1 \mathrm{~min}$;

- Following this, PEEP will be increased to $35 \mathrm{cmH}_{2} \mathrm{O}$ with other parameters maintained for $1 \mathrm{~min}$;

- Lastly, PEEP will be increased to $45 \mathrm{cmH}_{2} \mathrm{O}$ with other parameters maintained for $2 \mathrm{~min}$.

Recruitment will be terminated if one or more of the following signs of clinical deterioration are observed: 
Table 2 Summary of mechanical ventilation procedures in the ART strategy group vs. ARDSNet strategy group

\begin{tabular}{|c|c|c|}
\hline Procedure & $\begin{array}{l}\text { ART strategy: maximum alveolar recruitment } \\
\text { maneuver associated with PEEP titration }\end{array}$ & ARDSNet strategy \\
\hline Alveolar recruitment maneuver & Yes (see Figure 1) & No \\
\hline Ventilation mode & Volume-controlled & Volume-controlled \\
\hline $\begin{array}{l}\text { Target plateau pressure and } \\
\text { driving pressure }\end{array}$ & Plateau $\leq 30 \mathrm{cmH}_{2} \mathrm{O}$ & Plateau $\leq 30 \mathrm{cmH}_{2} \mathrm{O}$ \\
\hline Target tidal volume & 4 to $6 \mathrm{~mL} / \mathrm{kg}$ of predicted body weight & 4 to $6 \mathrm{~mL} / \mathrm{kg}$ of predicted body weight \\
\hline Respiratory rate and $\mathrm{pH}$ goal & 6 to $35 / \mathrm{min}$, adjusted for $\mathrm{pH} \geq 7.30$ if possible & 6 to $35 / \mathrm{min}$, adjusted for $\mathrm{pH} \geq 7.30$ if possible \\
\hline I:E ratio & $1: 1$ to $1: 2 ;$ flow $60 \mathrm{~L} / \mathrm{min}$; inspiratory pause $0.5 \mathrm{~s}$ & $1: 1$ to $1: 2 ;$ flow $60 \mathrm{~L} / \mathrm{min}$; inspiratory pause $0.5 \mathrm{~s}$ \\
\hline \multicolumn{3}{|l|}{ Oxygenation goals } \\
\hline $\mathrm{PaO}_{2}$ & 60 to $80 \mathrm{mmHg}$ & 55 to $80 \mathrm{mmHg}$ \\
\hline $\mathrm{SpO}_{2}$ & 90 to $95 \%$ & 88 to $95 \%$ \\
\hline PEEP and $\mathrm{FiO}_{2}$ adjustment & $\begin{array}{l}\text { PEEP titration } 2 \mathrm{cmH}_{2} \mathrm{O} \text { above PEEP value associated } \\
\text { with maximum compliance. } \mathrm{FiO}_{2} \text { titration adjusted } \\
\text { according to oxygenation goals }\end{array}$ & According to PEEP/FiO ${ }_{2}$ combination table \\
\hline Weaning & $\begin{array}{l}\text { After } 24 \mathrm{~h} \text { with } \mathrm{PaO}_{2} / \mathrm{FiO}_{2} \geq 300 \text { (or stable/ascending) } \\
\text { start weaning from PEEP } 2 \mathrm{cmH}_{2} \mathrm{O} \text { every } 8 \mathrm{~h} \text {. Consider } \\
\text { pressure support ventilation after PEEP } \leq 14 \mathrm{cmH}_{2} \mathrm{O} \text {. } \\
\text { Spontaneous ventilation test in PS }=5 \mathrm{cmH}_{2} \mathrm{O} \text { and } \\
\text { PEEP }=5 \mathrm{cmH}_{2} \mathrm{O} \text {. Routine use of NIV immediately after } \\
\text { extubation is encouraged }\end{array}$ & $\begin{array}{l}\text { Weaning from PEEP according to table of PEEP } \\
\text { and } \mathrm{FiO}_{2} \text { combinations. Consider pressure support } \\
\text { ventilation after PEEP } \leq 14 \mathrm{cmH}_{2} \mathrm{O} \text {. Spontaneous } \\
\text { ventilation test in } \mathrm{PS}=5 \mathrm{cmH}_{2} \mathrm{O} \text { and } \mathrm{PEEP}=5 \mathrm{cmH}_{2} \mathrm{O} \text {. } \\
\text { Routine use of NIV immediately after extubation is } \\
\text { encouraged }\end{array}$ \\
\hline
\end{tabular}

heart rate $>150$ or $<60 \mathrm{bpm}$; decrease of mean arterial blood pressure $<65 \mathrm{mmHg}$ or decrease of systolic blood pressure $<90 \mathrm{mmHg}$; decrease of $\mathrm{SpO}_{2}<88 \%$ for $>30 \mathrm{~s}$; acute atrial fibrilation, atrial flutter or ventricular tachycardia.

If recruitment is interrupted, physicians should proceed to PEEP titration, but should not repeat recruitment after titration (see next section 'PEEP titration and new recruitment'). If a patient remains unstable while PEEP is titrated, then PEEP titration should be interrupted and the patient should be placed on the ARDSNet protocol. In this case, recruitment should be considered later if the patient's condition stabilizes.

\section{PEEP titration and new recruitment}

Right after completing recruitment, PEEP will be set to $23 \mathrm{cmH}_{2} \mathrm{O}$. Ventilatory mode will be set to

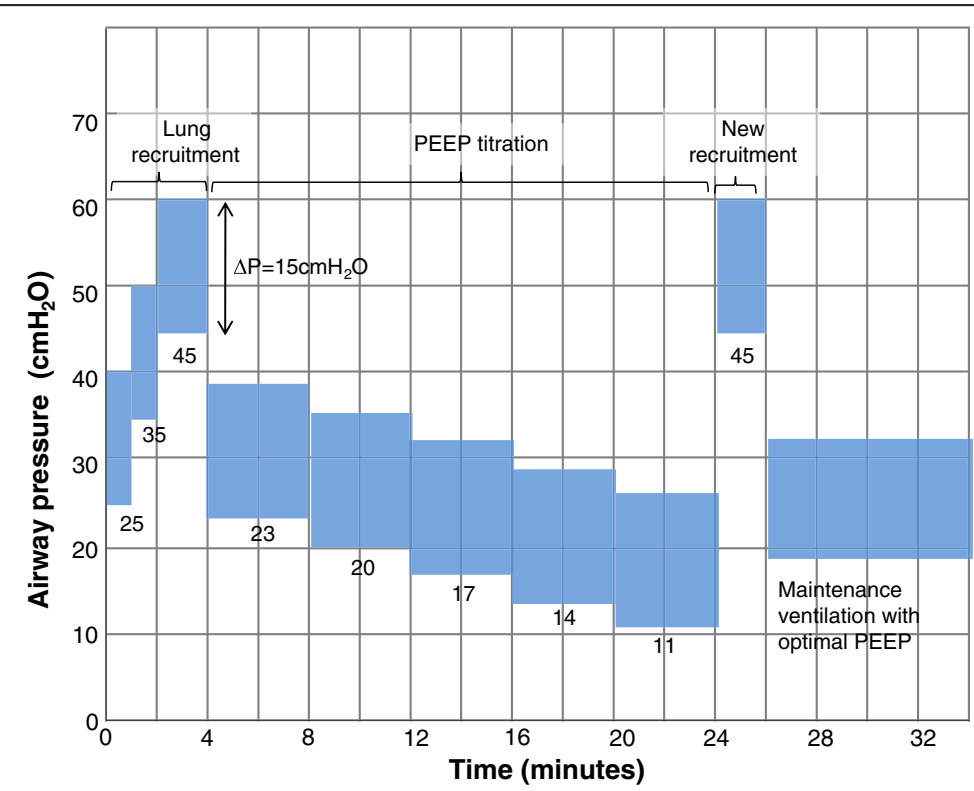

Figure 1 ART strategy: maximum alveolar recruitment maneuver associated with PEEP titration. 
volume-controlled, tidal volume to $5 \mathrm{~mL} / \mathrm{kg}$ of predicted body weight, respiratory rate to $20 / \mathrm{min}$, flow to $30 \mathrm{~L} / \mathrm{min}$ (square wave) and $\mathrm{FiO}_{2}$ to $100 \%$. After 4 min, static compliance of the respiratory system will be calculated and recorded (inspiratory pause $\geq 2 \mathrm{~s}$ required to reach plateau pressure). In sequence, PEEP will be decreased in steps of 20, 17, 14 , and $11 \mathrm{cmH}_{2} \mathrm{O}$ and the corresponding static compliance of the respiratory system will be recorded after each $4 \mathrm{~min}$.

Optimal PEEP will be the PEEP associated with the best static compliance plus $2 \mathrm{cmH}_{2} \mathrm{O}$. If a 'plateau' of best compliance is achieved, that is, more than one PEEP level associated with the best compliance, then the higher of the PEEP levels within the 'plateau' plus $2 \mathrm{cmH}_{2} \mathrm{O}$ is considered the optimal PEEP.

If falls in compliance are verified in two consecutive steps, the PEEP level with the highest compliance plus $2 \mathrm{cmH}_{2} \mathrm{O}$ is the optimal PEEP. In this case, there is no need to measure compliance on lower PEEP levels. After the PEEP titration phase, a new alveolar recruitment will be performed. The mechanical ventilator will be reset to pressure-controlled mode; respiratory rate to $10 / \mathrm{min}$; I:E ratio to $1: 1$, driving pressure to $15 \mathrm{cmH}_{2} \mathrm{O}, \mathrm{FiO}_{2}$ to $100 \%$ and PEEP adjusted to $45 \mathrm{cmH}_{2} \mathrm{O}$. These parameters will be maintained for $2 \mathrm{~min}$.

\section{Maintenance ventilation}

Following the new alveolar recruitment, the maintenance ventilation will be set: volumecontrolled mode, tidal volume of $5 \mathrm{~mL} / \mathrm{kg}$ of predicted body weight. If plateau pressure $>30$ $\mathrm{cmH} 2 \mathrm{O}$, reduce to $4 \mathrm{~mL} / \mathrm{kg}$ of predicted body weight. Minimum and maximum tidal volumes are 4 $\mathrm{mL} / \mathrm{kg}$ and $6 \mathrm{~mL} / \mathrm{kg}$ of predicted body weight. Flow of $60 \mathrm{~L} / \mathrm{min}$, descending waveform, inspiratory pause of $0.5 \mathrm{~s}$, I:E ratio of $1: 1$ to $1: 2$, respiratory rate to maintain the same minute ventilation prior to randomization, PEEP adjusted to optimal PEEP (PEEP value at maximum compliance plus $2 \mathrm{cmH}_{2} \mathrm{O}$ ) and $\mathrm{FiO}_{2}$ adjusted for $\mathrm{SpO}_{2} \geq 90 \%$ and $\leq 95 \%$.

5. When to repeat a recruitment maneuver Repetition of the maximum alveolar recruitment maneuver will be considered only when the initial maneuver is successful, which we defined as an increase of $\mathrm{PaO}_{2} / \mathrm{FiO}_{2}$ ratio $>100$ after maneuver. If the initial maneuver is successful, it will be repeated in two situations:

- Every $24 \mathrm{~h}$ if $\mathrm{PaO}_{2} / \mathrm{FiO}_{2}$ ratio is $<250$ and a decrease in $\mathrm{PaO}_{2} / \mathrm{FiO}_{2}$ ratio $>50$ occurs. After the recruitment maneuver, PEEP should be set at the value it was before plus $2 \mathrm{cmH}_{2} \mathrm{O}$. That is, there is no need to titrate PEEP again.

- If an accidental disconnection of the respiratory circuits occurs and PEEP is $\geq 12 \mathrm{cmH}_{2} \mathrm{O}$. After the recruitment maneuver, PEEP should be set at the same level it was before disconnection. There is no need to titrate PEEP again.

6. Adjustments in tidal volume and respiratory rate Adjustments in tidal volume and respiratory rate are the same for ART group and ARDSNet group, and is described below.

Respiratory rate and tidal volume must be adjusted to achieve the arterial $\mathrm{pH}$ goal: between 7.30 and 7.45. The $\mathrm{pH}$ is measured when clinically indicated.

\section{Management of alkalemia and acidemia}

- Alkalemia ( $\mathrm{pH}>7.45)$ : reduce respiratory rate, if possible

- Mild acidemia $(7.15 \leq \mathrm{pH}<7.30)$ :

- If $\mathrm{PaCO}_{2} \leq 40 \mathrm{mmHg}$, consider sodium bicarbonate and, if possible, treat the cause of metabolic acidosis

- If $\mathrm{PaCO}_{2}>40$ mmHg:

O Increase respiratory rate up to a maximum of 35 aiming a $\mathrm{pH}>7.30$ or $\mathrm{PaCO}_{2}<40 \mathrm{mmHg}$, whichever occurs first. If there is associated metabolic acidosis, it should also be managed.

O If the respiratory rate $=35$ and $\mathrm{pH}$ is between 7.15 and 7.30 , there is no need of additional measures.

- Severe acidemia ( $\mathrm{pH}<7.15)$ :

- If $\mathrm{PaCO}_{2} \leq 40 \mathrm{mmHg}$, consider sodium bicarbonate and, if possible, treat the cause of metabolic acidosis.

- If $\mathrm{PaCO}_{2}>40 \mathrm{mmHg}$

- Increase respiratory rate to 35 . If there is associated metabolic acidosis, it should also be managed.

- If respiratory rate $=35, \mathrm{pH}<7.15$, and $\mathrm{PaCO}_{2}$ $>40 \mathrm{mmHg}$, increase tidal volume in steps of $1 \mathrm{~mL} / \mathrm{kg}$, up to $6 \mathrm{~mL} / \mathrm{kg}$ of predicted body weight. In this condition, the plateau pressure goal of $30 \mathrm{cmH}_{2} \mathrm{O}$ can be exceeded.

- If respiratory rate $=35, \mathrm{pH}<7.15, \mathrm{PaCO}_{2}$ $>40 \mathrm{mmHg}$, and tidal volume is $6 \mathrm{~mL} / \mathrm{kg}$ of predicted body weight, increase tidal volume to $7 \mathrm{~mL} / \mathrm{kg}$ of predicted body weight.

- If the situation remains unresolved (respiratory rate $=35, \mathrm{pH}<7.15, \mathrm{PaCO}_{2}>40 \mathrm{mmHg}$, and tidal volume is $7 \mathrm{~mL} / \mathrm{kg}$ of predicted body weight) 
increase tidal volume to $8 \mathrm{~mL} / \mathrm{kg}$ of predicted body weight.

7. Refractory hypoxemia Refractory hypoxemia is defined as a $\mathrm{PaO}_{2}<55 \mathrm{mmHg}$ or $\mathrm{SpO}_{2}<88 \%$ with $\mathrm{FiO}_{2}=100 \%$. The following sequential actions should be taken for patients presenting with refractory hypoxemia:

- Prone position;

- If the patient does not improve, then start inhaled nitric oxide, if available, beginning with $5 \mathrm{ppm}$ and increasing in steps of $5 \mathrm{ppm}$ until there is improvement in oxygenation;

- Final step is to initiate extracorporeal membrane oxygenation (ECMO) if available.

8. Weaning from mechanical ventilation

PEEP weaning can start $24 \mathrm{~h}$ after the initial alveolar recruitment maneuver. PEEP can be decreased $2 \mathrm{cmH}_{2} \mathrm{O}$ each $8 \mathrm{~h}$ as long as the $\mathrm{PaO}_{2} /$ $\mathrm{FiO}_{2}$ ratio are $>300$. In case of not achieving $\mathrm{PaO}_{2} /$ $\mathrm{FiO}_{2}$ ratio $>300$ after alveolar recruitment, PEEP can be decreased $2 \mathrm{cmH}_{2} \mathrm{O}$ each $8 \mathrm{~h}$ if $\mathrm{PaO}_{2} / \mathrm{FiO}_{2}$ ratio is similar or greater than the day before. Other than the PEEP weaning procedure described above, the rest of the weaning method is equal in the ART and ARDSNet groups, and is described below.

Pressure support (PS) ventilation can be initiated in alert patients when PEEP $\leq 14 \mathrm{cmH}_{2} \mathrm{O}$. Start with PS of $10 \mathrm{cmH}_{2} \mathrm{O}$ or less to achieve tidal volume of $6 \mathrm{~mL} / \mathrm{kg}$ of predicted body weight. PS ventilation can be reduced from 2 to $4 \mathrm{cmH}_{2} \mathrm{O}$ twice daily as long as respiratory frequency is $<28$ breaths per min (and there are no other signs of discomfort). In patients with signs of discomfort (for example, those with $\geq 30$ breaths per minute) investigators should consider other causes (such as pain or anxiety) before increasing PS. If PS over $14 \mathrm{cmH}_{2} \mathrm{O}$ is needed, then volume-controlled ventilation will be resumed.

Table 3 Type of assessment and criteria for performing a spontaneous breathing test

\begin{tabular}{|c|c|}
\hline Clinical assessment & Improvement of acute process (ARDS and associated conditions) leading to intubation and mechanical ventilation \\
\hline & Patient is alert and cooperative \\
\hline & Chest pain is controlled \\
\hline & Adequate cough (moderate to high strength) \\
\hline & Absence of excessive tracheobronchial secretion \\
\hline & No signs of respiratory distress: \\
\hline & Nostril flaring \\
\hline & Use of accessory muscles of respiration (suprasternal and/or intercostal retraction) \\
\hline & Paradoxical movements of the chest/abdomen \\
\hline \multirow[t]{16}{*}{ Objective measurements } & Respiratory stability: oxygenation \\
\hline & PEEP $\leq 10 \mathrm{cmH}_{2} \mathrm{O}$ \\
\hline & Support pressure $\leq 10 \mathrm{cmH}_{2} \mathrm{O}$ \\
\hline & $\mathrm{PaO}_{2} / \mathrm{FiO}_{2} \geq 250$ (consider weaning if $\geq 150$ ) \\
\hline & $\mathrm{SpO}_{2}>90 \%$ under $\mathrm{FiO}_{2} \leq 40 \%$ \\
\hline & Respiratory stability: function \\
\hline & Respiratory rate $\leq 35$ breaths/min \\
\hline & Minute volume $<10 \mathrm{~L} / \mathrm{min}$ \\
\hline & Respiratory rate/tidal volume $(\mathrm{L})<105$ breath/min/L \\
\hline & No significant respiratory acidosis $(\mathrm{pH} \geq 7.25)$ \\
\hline & Cardiovascular stability \\
\hline & Heart rate $<140 \mathrm{bpm}$ \\
\hline & Systolic blood pressure $>90$ and $<160 \mathrm{mmHg}$ \\
\hline & Without vasoconstrictor/inotropic drugs (or low doses) \\
\hline & Neurological stability \\
\hline & Patient alert and cooperative - SAS 4 (acceptable: slightly drowsy patient (SAS 3) slightly agitated (SAS 5)) \\
\hline
\end{tabular}


Daily assessments to attempt the spontaneous breathing test will be performed preferably during the morning. The criteria shown on Table 3 will be considered to start the spontaneous breathing test. Spontaneous ventilation test will be performed using PS mode, with PEEP of $5 \mathrm{cmH}_{2} \mathrm{O}$, PS of 5 $\mathrm{cmH}_{2} \mathrm{O}$, for $30 \mathrm{~min}$. Criteria to diagnose failure in spontaneous ventilation test are presented in Table 4.

Patients who pass the spontaneous breathing test can be extubated. Cuff leak test is optional. Systemic steroids for patients intubated for long periods, with the aim to prevent upper airway obstruction after extubation, are also optional. Non-invasive ventilation should be considered for all patients. This is strongly recommended for patients at high risk of extubation failure, such as: patients who do not meet all the criteria for extubation (for example, respiratory rate/ tidal volume $(\mathrm{L}) \geq 105$ breaths $/ \mathrm{min} / \mathrm{L}$ ); and patients who failed the spontaneous breathing test at least once.

\section{ARDSNet strategy (conventional ventilation)}

\section{Maintenance ventilation}

If patients are assigned to the ARDSNet strategy, no alveolar recruitment will be performed. The conventional mechanical ventilation strategy that will be used in this group has been described previously $[9,18]$. Initial ventilator settings will be:

- Volume-controlled mode;

- Plateau pressure $\leq 30 \mathrm{cmH}_{2} \mathrm{O}$;

- Tidal volume of $5 \mathrm{~mL} / \mathrm{kg}$ of predicted body weight. If plateau pressure $>30 \mathrm{cmH}_{2} \mathrm{O}$, reduce to $4 \mathrm{~mL} / \mathrm{kg}$ of predicted body weight. Minimum and maximum tidal volumes are $4 \mathrm{~mL} / \mathrm{kg}$ and $6 \mathrm{~mL} / \mathrm{kg}$ of predicted body weight;

- Respiratory rate will be adjusted with the aim of maintaining the same minute volume recorded before study entry. Maximum respiratory rate will be $35 / \mathrm{min}$;

- Flow 60 L/min;

- Descending inspiratory flow;

- Inspiratory pause $0.5 \mathrm{~s}$;

- I:E ratio between 1:1 a 1:2;

- PEEP and $\mathrm{FiO}_{2}$ adjusted according to the ARDSNet (Table 1) aiming to keep the oxygenation goals: $\mathrm{SpO}_{2}$ between $88 \%$ and $95 \%$, and $\mathrm{PaO}_{2}$ between $55 \mathrm{mmHg}$ and $80 \mathrm{mmHg}$.

2. Adjustments in tidal volume and respiratory rate These are the same as described for the ART Group above.

3. Refractory hypoxemia

Table 4 Type of assessment and criteria for failure of the spontaneous breathing test

\begin{tabular}{|c|c|}
\hline Clinical assessment & Agitation, excessive anxiety, or depressed level of consciousness \\
\hline & Major sweating \\
\hline & Cyanosis \\
\hline & Signs of respiratory distress: \\
\hline & Nostril flaring \\
\hline & Use of accessory muscles of respiration (suprasternal and/or intercostal retraction) \\
\hline & Paradoxical movements of the chest/abdomen \\
\hline \multirow[t]{12}{*}{ Objective measurements } & Respiratory instability: oxygenation \\
\hline & $\mathrm{SpO}_{2}<90 \%$ \\
\hline & Respiratory instability: function \\
\hline & Respiratory rate $>35$ breaths/min or increase $>10$ breaths $/$ min \\
\hline & Respiratory rate/tidal volume $(\mathrm{L})<105$ breath/min/L \\
\hline & If arterial blood gases measured: \\
\hline & $\mathrm{pH}<7.25$ \\
\hline & $\mathrm{PaCO}_{2}>50 \mathrm{mmHg}$ or increase $>8 \mathrm{mmHg}$ \\
\hline & Cardiovascular instability \\
\hline & Heart rate $<140$ bpm \\
\hline & Systolic blood pressure $<90$ and $>160 \mathrm{mmHg}$ \\
\hline & Onset of arrhythmias (for example, frequent ventricular extrasystole) \\
\hline
\end{tabular}


The definition of refractory hypoxemia is the same as for the ART group, that is, $\mathrm{PaO}_{2}<55 \mathrm{mmHg}$ or $\mathrm{SpO}_{2}<88 \%$ with $\mathrm{FiO}_{2}=100 \%$.

The sequence of actions to be taken for patients presenting with refractory hypoxemia is similar, except for the first two steps, as is describe below:

- Increase PEEP up to $24 \mathrm{cmH}_{2} \mathrm{O}$ and $\mathrm{FiO}_{2}$ to $100 \%$ (as in the right end of the ARDSNet table (Table 1));

- If no improvement is achieved, than PEEP should be increased 2 to $5 \mathrm{cmH}_{2} \mathrm{O}$ each step up to 34 $\mathrm{cmH}_{2} \mathrm{O}$ or until $\mathrm{PaO}_{2}$ is between $55 \mathrm{mmHg}$ and $80 \mathrm{mmHg}$ or $\mathrm{SpO}_{2}$ is $88 \%$; to $95 \%$.

- If no improvement is achieved, PEEP should be lowered to $24 \mathrm{cmH}_{2} \mathrm{O}$, and the sequence described above to manage refractory hypoxemia in the ART group should be followed. First step, is to put the patient in the prone position;

- If the patient does not improve, then start inhaled nitric oxide, if available, beginning with $5 \mathrm{ppm}$ and increasing in steps of $5 \mathrm{ppm}$ until there is improvement in oxygenation;

- Final step is to initiate ECMO if available.

4. Weaning from mechanical ventilation

Weaning of PEEP and $\mathrm{FiO}_{2}$ is done following the ARDSNet table (Table 1).

Other aspects of weaning are the same as described above for the ART group.

\section{Blinding}

Since the intervention will be administered to criticallyill patients on mechanical ventilation (that is, mostly sedated), blinding of these patients is not necessary. Because this is a non-pharmacological intervention, blinding of the medical team is not feasible. There is no need for a committee to validate the primary study outcome (28-day survival), and therefore outcome adjudicators will not be blinded.

\section{Outcomes}

The primary outcome of the ART is 28-day survival. The secondary outcomes are: (1) length of ICU stay; (2) length of hospital stay; (3) pneumothorax requiring chest tube at 7 days; (4) barotrauma (any pneumothorax, pneumomediastinum, subcutaneous emphysema, or pneumatocele $>2 \mathrm{~cm}$ after randomization) at 7 days; (5) mechanical ventilation-free from days 1 to 28 ; (6) ICU survival; (7) in-hospital survival; and (8) 6-month survival.

\section{Data collection and management}

Study follow-up and the variables that will be collected are described below.

\section{Screening and eligibility data (Day 0)}

- Patient's initials, gender, date of birth

- Verification of ARDS criteria

- Screening inclusion and exclusion criteria

- Respiratory variables (tidal volume, plateau pressure, total respiratory rate, $\mathrm{PEEP}, \mathrm{FiO}_{2}$ ) while awaiting informed consent

- Final eligibility criteria:

- $\mathrm{PaO}_{2}$ at $\mathrm{FiO}_{2}$ of $100 \%$ and PEEP of $10 \mathrm{cmH}_{2} \mathrm{O}$ (or greater if previous PEEP were $\geq 16 \mathrm{cmH}_{2} \mathrm{O}$ )

- Estimated time from onset of ARDS (onset of ARDS based on arterial blood gases until randomization)

\section{Baseline Data (Day 0)}

The following data will be recorded at the baseline visit:

- Weight (measures with a weighing scale)

- Height

- SAPS 3 (at ICU admission)

- Respiratory variables (Tidal volume, Plateau pressure, Total respiratory rate, $\mathrm{PEEP}, \mathrm{FiO}_{2}$ )

- Sequential organ failure assessment (SOFA)

- Cause of ARDS

- Days of intubation prior randomization

Treatment Data (1 $h$ after start of intervention)

The following data regarding treatment will be assessed for patients randomized to ART strategy:

- Alveolar recruitment (for the group treated with maximum alveolar recruitment)

- Maximum PEEP reached

- If maximum alveolar recruitment is interrupted, the reason provided (list of criteria for interruption)

- The following data regarding treatment will be assessed for all patients:

- Respiratory variables of maintenance ventilation (Tidal volume, Plateau pressure, Total respiratory rate, $\mathrm{PEEP}, \mathrm{FiO}_{2}, \mathrm{PaO}_{2}, \mathrm{PaCO}_{2}$, Arterial $\mathrm{pH}$ )

- Hemodynamic variables (Heart rate, Mean blood pressure, Use of noradrenaline and dopamine)

\section{1-Day Follow-Up}

- Respiratory variables of maintenance ventilation (Tidal volume, Plateau pressure, Total respiratory rate, $\mathrm{PEEP}, \mathrm{FiO}_{2}, \mathrm{PaO}_{2}, \mathrm{PaCO}_{2}$, Arterial pH)

- Water balance and weight (weighing scale) 


\section{3-Day Follow-Up}

- Respiratory variables of maintenance ventilation (Tidal volume, Plateau pressure, Total respiratory rate, $\mathrm{PEEP}, \mathrm{FiO}_{2}, \mathrm{PaO}_{2}, \mathrm{PaCO}_{2}$, Arterial $\mathrm{pH}$ )

- Water balance and weight (weighing scale)

\section{7-day follow-up}

- Vital status at day 7. If patient dies before day 7, the following variables should be collected:

- Date of death

- Death due to refractory hypoxemia

- Death due to refractory respiratory acidosis

- Death due to refractory barotrauma

- Number of days on mechanical ventilation

- Respiratory variables of maintenance ventilation (Tidal volume, plateau pressure, total respiratory rate, $\mathrm{PEEP}, \mathrm{FiO}_{2}, \mathrm{PaO}_{2}, \mathrm{PaCO}_{2}$, arterial $\mathrm{pH}$ )

- Water balance and weight (weighing scale)

- Co-interventions during the period (use of/ number of days using neuromuscular blockers; use of/number of days using continuous infusion of sedatives; use of/number of days using continuous infusion of narcotics; use of/number of days using noradrenaline or dopamine; use of/ number of days using corticoids; rescue therapies for refractory hypoxemia: prone position, nitric oxide, high frequency oscillatory ventilation, ECMO)

- Pneumothorax requiring chest tube drainage during the period

- Barotrauma (any pneumothorax, pneumomediastinum, subcutaneous emphysema, or pneumatocele $>2 \mathrm{~cm}$ after randomization) during the period

\section{Hospital discharge}

- Date of ICU discharge and vital status at ICU discharge

- Date of hospital discharge and vital status at hospital discharge

\section{8-day follow-up}

- Days on mechanical ventilation (considering the first 28 days after randomization)

- Vital status and date of death (for patients who died)

\section{6-month follow-up}

- Vital status and date of death (for patients who died)

\section{Clinical Data Management System (CDMS) and quality control}

Besides the 24-h concealed randomization, the ACT Clinic will provide data entry, data cleaning, and exportation for analysis. The system will also provide reports on the status of the study forms (completed forms, overdue forms), weekly study recruitment by center, and graphs of observed and expected cumulative recruitment.

Several procedures will assure data quality, including: (1) all investigators will attend a training session before the start of the study to standardize procedures, including data collection; (2) the investigators may contact the Study Coordinating Center to solve issues or problems that may arise; (3) data entry into the ACT-Clinic is subject to various checks for missing data, plausible, possible or non-permitted value ranges, and logic checks. Problems are informed by the system at the time of data entry; (4) statistical techniques to identify inconsistencies will be applied periodically (about every two weeks). The centers will be notified of the inconsistencies and asked to correct them; (5) statistical routines to identify fraud will be conducted periodically (every 90 days); (6) on-site monitoring will be conducted during study conduction; (7) the coordinating center will review detailed reports on screening, enrolment, follow-up, inconsistencies, and completeness of data. Immediate actions will follow to solve problems that arise.

\section{Sample size}

ART is an event driven study designed to last until 520 events (deaths within 28 days) are observed. This number of events is sufficient to detect a hazard ratio of 0.75 (that is, relative reduction in event rate of $25 \%$ ), considering a type I error of 5\%, $90 \%$ power, and a similar allocation of subjects to each group. Considering an event rate in the control group of 36\% (mean proportion of deaths in randomized studies conducted after 1994, when the definition of ARDS was first standardized) [3] we expect that about 1,620 patients will be needed to achieve the number of events planned. However, since this is an event driven study, the total sample size can vary depending on the event rate in the experimental and control groups.

\section{Statistical analysis plan}

All analysis will follow the intention-to-treat principle. Survival within 28 days (primary outcome) in both groups will be assessed using Kaplan-Meier curves and Cox proportional hazard models, without adjustment for other co-variates. Treatment effects on length of ICU stay, hospital stay, and number of mechanical ventilation-free days at 28 days will be analyzed using Mann-Whitney tests. Occurrence of pneumothorax and barotrauma will be evaluated using chi-square tests; ICU 
and in-hospital mortality will be evaluated with chisquare tests; 6-month survival will be analyzed using Kaplan-Meier curves and Cox proportional hazards models. Treatment effect on 28-day survival will be analyzed in the following subgroups: (1) $\mathrm{PaO}_{2} / \mathrm{FiO}_{2} \leq 100$ vs. >100; (2) SAPS 3 score <50 vs. $\geq 50$; 3) (pulmonary ARDS (pneumonia, aspiration, pulmonary contusion, near drowning) vs. extrapulmonary ARDS (non-pulmonary sepsis, trauma without pulmonary contusion, major surgery, multiple transfusions, traumatic brain injury, drug overdose, shock, other cause) (4) time of ARDS $\leq 36 \mathrm{~h} v s$. $>36$ to $<72 \mathrm{~h}$; (5) mechanical ventilation $\leq 2$ days, 3 to 4 days, $\geq 5$ days. Effects on subgroups will be evaluated using the chi-square test for homogeneity. Statistical significance is defined as $P<0.05$. All analyses will be carried out using the statistical software R (R Development Core Team, URL http://www. R-project.org - version 2.13) or STATA SE 11 for Windows (College Station, TX, USA).

\section{Ethical aspects}

Each investigator center will submit the study protocol to its institutional Research Ethics Board (REB). The study should start only after being approved by the REB. Written informed consent will be obtained from a legal representative of all participants. This study is in compliance with Brazilian and international declarations.

\section{Trial organization and management} Trial management team (TMT)

A team based on the Research Institute HCor, São Paulo, Brazil will manage the trial on a day-to-day basis. The TMT is comprised by the chief investigator, a project manager, a statistician, and a computer programmer.

The responsibilities of the TMT include:

- Planning and conducting the study: designing the protocol; designing the electronic case report forms (e-CRF); designing the operation guide; managing and controlling data quality; designing, testing, and maintaining the electronic data capture system; continuous data quality control; assisting the steering committee;

- Managing the research centers: selecting and training the research centers; helping the centers prepare a regulatory report to be submitted to the REBs and assisting the centers with the submission; monitoring recruitment rates and the actions to increase recruitment; monitoring follow-up and implementing actions to prevent follow-up losses; auditing; sending study materials to the research centers; producing a monthly study newsletter; developing supporting material for the study;
- Statistical analysis and research reporting: complete statistical analysis; helping to write the final manuscript.

\section{Trial steering committee (TSC)}

The TSC is responsible for the overall study supervision, assisting in developing the study protocol and preparing the final manuscript. All other study committees report to the TSC. The TSC members are investigators trained in designing and conducting randomized clinical trials, intensivists, respiratory therapists, and pulmonologists experienced in conducting multicenter randomized studies on ARDS.

\section{Trial centers}

Initially 80 centers would be invited to participate in the study, but the current goal is to involve 120 centers in the study. Details of the centers which accepted to participate in the trial at the time of this manuscript submission are given in the Appendix.

\section{Institutional support from the Brazilian Association of Intensive Care Medicine (Associação de Medicina Intensiva Brasileira (AMIB))}

The AMIB supports the ART study by means of the AMIB-Net. The AMIB-Net will assist with the selection and invitation of centers to participate in the ART, as well as facilitate the organization of meetings of researchers during national scientific meetings organized by the AMIB.

\section{Publication policy}

The ART study success depends on all its collaborators. Therefore, the primary results of the trial will be published under the name of ART Investigators. The contributions of all collaborators, their names and respective institutions, will be acknowledged in the manuscript. To safeguard the scientific integrity of the study, data from this study will be submitted to publication only after the final approval from the TSC.

\section{Data monitoring committee (DMC)}

The DMC is set up with independent epidemiologists and intensivists. The DMC is in charge of providing recommendations for the TSC of continuing the study as planned or discontinuing the recruitment based on evidence that the intervention causes increased mortality in the experimental group as compared to the control group. Interim analyses will be conducted after recruitment of approximately $33 \%$ and $66 \%$ of the sample. Based on these interim analyses, and, occasionally, on external evidence, the DMC shall decide whether there is evidence beyond a reasonable doubt that the treatment is clearly contraindicated in all patients or any subgroup. The criterion of evidence beyond a reasonable 
doubt is increased mortality at 28 days with the maximum lung recruitment strategy compared with the low PEEP strategy, with $P<0.01$. Otherwise, the TSC and other investigators will not be informed of the results of interim analyses. Considering previous evidence showing that: (1) early discontinuation of randomized trials due to benefits tends to produce biased estimates of effect (overestimation of the true effect), leading to erroneous medical guidelines and decisions [19]; (2) according to the ethical principle of non-maleficence, a new treatment should not be used until there is clear, objective evidence that it is beneficial; (3) clinical practice usually does not change unless there is fairly convincing evidence of the advantages of the new treatment, which would be undermined if the study is discontinued early due to benefits; the decision of early discontinuation of the experimental treatment due to benefits may not be advantageous for future patients, or may contribute to mislead guidelines [20]. For these reasons, early discontinuation of the study due to benefits of the experimental treatment is not planned.

\section{Discussion}

ARDS is a common problem in intensive care associated with a very large in-hospital mortality rate, in spite of advances in therapy [3]. Maximum alveolar recruitment followed by PEEP titration is a relatively simple, inexpensive, and widely available intervention with potential to improve the prognosis of patients with ARDS. In most patients with ARDS, this strategy is able to keep open more than $90 \%$ of lung mass, improving oxygenation and preventing atelectrauma [13]. However, the effects of this strategy on patient important outcomes remain to be established. Therefore, evidence from well designed and conducted trials to solve this question is essential.

The ART was planned to be the largest randomized trial involving ARDS patients conducted to date. It will provide a precise and reliable estimate of the effect of alveolar recruitment and PEEP titration on survival of ARDS patients compared to the ARDSNet strategy, currently the evidence-based best approach for mechanical ventilation.

If our study finds that the maximum alveolar recruitment plus PEEP titration is not beneficial, this will play a role in changing medical practice since maximum alveolar recruitment associated with high levels of PEEP is routinely used by many intensivists. On the other hand, if the study demonstrates that maximum alveolar recruitment associated with PEEP titration increases survival in patients with ARDS, this will represent a valuable improvement for the treatment of ARDS patients.

\section{Trial status}

The ART is currently ongoing in 103 sites in Brazil, Colombia, Italy, and Mexico. Enrollment started in December 2011 in one site. Now, 40 sites are actively screening for patients, and the remaining are undergoing REB evaluation. As of June 1, 2012, we had already enrolled 63 patients. We are inviting centers in other countries to join us.

\section{Appendix}

The ART Investigators consists of:

Writing and Steering Committee: Alexandre B. Cavalcanti (Co-Chair), Otávio Berwanger, Érica A Suzumura, Marcelo BP Amato, Fernando S Tallo, Ederlon AC Rezende, José MM Telles, Edson Romano, Hélio P Guimarães, Marisa M Regenga, Luzia N Takahashi, Cassiano Teixeira, Roselaine P Oliveira, Vitor O Carvalho, Fredi A Díaz-Quijano, Carlos RR Carvalho (Co-Chair and Senior Investigator).

Trial Management Team: Alexandre B Cavalcanti, Érica A Suzumura, Otávio Berwanger, Alessandra A Kodama, Gisele FM Ribeiro, Matheus O Abreu, Ivonaldo M Oliveira.

Data Monitoring Committee: Gordon Guyatt (Chair), Niall Ferguson, Stephen Walter.

Trial centers: Brazil: Hospital de Urgências e Emergências de Rio Branco-HUERB, Rio Branco-AC: Márcia O. M. Vasconcelos, Valério J. Segundo, Íris L. Ferraz, Rosicley S. Silva; Hospital e Pronto-Socorro 28 de Agosto, ManausAM: Wilson de Oliveira Filho, Nelson B. Silva, Débora C. B. Heirel, Rodrigo R. Takatani, Jefferson A. Sousa Neto, Jerônimo C. B. Neto, Samara D. Almeida, Gauco Chamy; UNIMED Manaus, Manaus-AM: Wilson de Oliveira Filho, Graciliano J. L. Gonçalves Neto, Samara D. Almeida, Alysson P. Dias, Rozangela R. Silva; Fundação Hospital Adriano Jorge, Manaus-AM: Roberta C. Tavares, Márcia L. V. D. Souza, Janaína C. Decio; Hospital Santa Izabel - Santa Casa de Misericórdia da Bahia, SalvadorBA: Cyntia M. L. S. Lima, Fleury Ferreira Neto; Hospital Regional de Juazeiro - Gestão IMIP, Juazeiro-BA: Kátia R. Oliveira, Polyana P. L. C. Dias, André L. S. B. Brandão, Joroastro E. Ramos Jr, Paula T. Vasconcelos; Hospital Universitário Prof. Edgar Santos, Salvador-BA: Dimitri G. Flôres, Gilvan R. Pinheiro Filho, Isaac G. Andrade; Hospital Espanhol, Salvador-BA: Amadeu Martinez, Gustavo G. P. França, Lívia L. Monteiro, Emmanuel I. S. Correia, Wagner Ribeiro, Antonio J. Pereira, Wandalvo Andrade, Petrônio A. Leite, Gilvan R. Pinheiro Filho; Hospital Geral Roberto Santos, Salvador-BA: Dimitri G. Flôres; Hospital de Messejana, Fortaleza-CE: José E. Filgueira Feto, Marcelo A. Holanda; Hospital Regional de Samambaia, Brasilia-DF: Fábio F. Amorim, Silviano B. Margalho; Hospital Regional da Asa Norte - HRAN, Brasilia-DF: Sergio M. Domingues Jr, Claiton S. Ferreira, Cassia M. Ferreira, Livia A. Rabelo, Juliana N. Duarte, Fernando B. Lima, Inês 
A. L. Kawaguchi; Hospital Santa Luzia, Brasilia-DF: José A. Araújo Neto, Marcelo O. Maia; Hospital Santa Lucia, Brasilia-DF: Fabiano G. Correa; Hospital Anchieta, Brasilia-DF: Rubens A. B. Ribeiro; Centro Integrado de Atenção à Saúde - CIAS, Vitória-ES: Eliana Caser, Cora L. C. B. Moreira, Antonielen Marcilino, Jansen G. Falcão, Karinne R. Jesus, Leo Tcherniakovisk, Victor G. Dutra; Hospital Evangélico de Cachoeiro de Itapemirin, Cachoeiro de Itapemirim-ES: Marlus M. Thompson; Vitória Apart Hospital, Vitória-ES: Claudio Piras, Jonas Giuberti Jr, Albano S. Silva; Vila Velha Hospital, Vila Velha-ES: José R. P. Santos, Jorge L. Potratz, Ludmila N. Paula, Giovana G. Bozi, Bruno C. Gomes; Hospital das Clínicas - UFES, Vitória-ES: Paula F. Vassallo, Edson P. Rocha, Maria H. B. S. Lima; Hospital das Clínicas (UFG), Goiania-GO: Denise M. Ferreira, Fernanda A. F. Gonçalves, Sheila A. Pereira, Marciano S. Nobrega, Carlos R. Caixeta; Hospital Geral Tarquínio Lopes Filho, São Luiz-MA: Ana P. P. Moraes; UDI Hospital, São Luiz-MA: Alexandre G. R. Carvalho; Santa Casa da Misericórdia de Ouro Preto, Ouro Preto-MG: Janine D. Alves; Hospital Eduardo de Menezes, Belo Horizonte-MG: Frederico B. Carvalho, Fabiana B. R. Moreira, Claudia M. Starling, Wivian A. D. Couto; Fundação Hospitalar São Sebastião, Tres Corações-MG: Wesley S. Bitencourt; Hospital Cônego Monte Raso, Baependi-MG: Wesley S. Bitencourt; Hospital Municipal Odilon Behrens, Belo Horizonte-MG: Frederico B. Carvalho, Daniela C. Peixoto, Ivana L. V. Carvalho, Silvângela G. A. Silva, Livia R. S. M. Felizardo, Francine J. Magalhães Nascimento, Priscila J. C. D. Santos, Camila C. Zanta, Marcele F. Martins; Hospital São Lucas de Governador Valadares, Governador ValadaresMG: Sérgio A. Naves, Fabiano D. Silva, Gilberto Laube Jr; Santa Casa de Caridade de Diamantina, Diamantina, MG: Endi L. Galvão, Marcelo F. Sousa, Marcia M. F. Souza, Fernanda L. G. Carvalho; Hospital Santa Lúcia - Hospital do Coração de Poços de Caldas, Poços de Caldas-MG: Ricardo R. Bergo; Hospital Regional de Mato Grosso do Sul Rosa Pedrossian, Campo Grande-MS: Claudnei M. Rezende, Edys Y. Tamazato, Saturnino Campo Sarat Jr, Patrícia S. Almeida, Anthony G. Gorski; Hospital Universitário - Universidade Federal da Grande Dourados, Dourados-MS: Mirna Matsui, Ervin Eberhart Neto, Silmara H. Nomoto, Zildamara B. Lima, Alexandre S. Inagaki, Fernando S. U. Gil, Mario F. A. Araújo, Aline E. Oliveira, Tiago A. Correa, Angela Mendonça; Hospital de Clínicas Gaspar Vianna, Belém-PA: Helder Reis, Saul R. Carneiro; Carlos Castanelo, Edward Coelho Jr, Karine A. E. H. Amaral; Hospital Saúde da Mulher, Belém-PA: Leila R. M. Rego, Adenard F. C. Cunha, Williams F. Barra, Maurício Carneiro, Roseane A. Batista, Karina K. Zoghbi; Fundação Santa Casa de Misericórdia do Pará, Belém, PA: Nelma J. N. Machado, Reinaldo Ferreira, Pablo Apoena, Rosangela M. Leão;
Hospital de Emergência Trauma Senador Humberto Lucena, João Pessoa-PB: Eliauria R. Martins, Marcelo E. Oliveira, Isaura Odir, Wladimy Kleber, Daniele Tavares; Hospital UNIMED João Pessoa, João Pessoa-PB: Eliauria R. Martins, Marcelo E. U. Araújo, Yuzeth Nóbrega Brilhante, Daniele C. C. Tavares, Wladmy Kleber, Waneska L. N. Carvalho, Geórgia F. P. Winveler; Hospital Alfa, Recife-PE: Aldir Chagas Filho, Raphael Ali Cavalcanti; Hospital Evangélico de Londrina, Londrina-PR: Cintia M. C. Grion, Andrezza T. J. B. Reis, Josiane Festti, Francielli M. P. Gimenez; Hospital Universitário Regional do Norte do Paraná, Londrina-PR: Cintia M. C. Grion, Alexandre S. Larangeira, Lucienne T. Q. Cardoso, Ana L. Mezzaroba, Thiago S. Giancursi, Ivanil A. M. Kauss; Hospital São Lucas/FAG, Cascavel-PR: Péricles A. D. Duarte, Tatiane C. Tozo, Priscila Peliser; Hospital Universitário Regional de Maringá, Maringá-PR: Almir Germano, Sanderland J. T. Gurgel, Sandra R. B. Silva, Cristina M Kuroda, Andrea Herek, Sergio S. Yamada; Hospital Santa Casa - Campo Mourão, Campo Mourão-PR: Paulo M. Schiavetto; Hospital Santa Tereza de Guarapuava, Guarapuava-PR: Natacha Wysocki, Rosely R. Matsubara; Hospital de Clínicas de Padre Miguel, Rio de Janeiro-RJ: João A. L. Sales Jr, Maria P. Laprovita; Hospital Prontocardio, Campos dos Goytacazes-RJ: Felipe M. Pena, Alexandre Sá; Clínica São Vicente, Rio de Janeiro-RJ: Arthur Vianna; Hospital Barra D'Or, Rio de Janeiro-RJ: Juan C. Verdeal, Glória A. Martins, Diamantino R. Salgado; Hospital Monte Sinai, Ariquemes-RO: Adalberto M. Coelho, Milena P. P. M. Coelho, Aline S. Morong, Rodolfo M. B. Poquiriqui, Ana P. Ferreira, Debora N. L. Lucena, Nathalia F. Marino, Monique A. Moreira, Cristiana C. S. Uratani; Hospital Estadual e Pronto Socorro João Paulo II, Porto Velho RO: Marta A. Severino, Patrícia N. Silva, Luciana G. Medeiros, Francisco G. Chaves Filho, Daniela M. Q. S. Guimarães; Hospital Geral de Roraima, Boa Vista-RR: Valéria M. C. Rezende, Roberto C. C. Carbonell, Renata S. Trindade; Hospital Nossa Senhora da Conceição, Porto Alegre-RS: José A. S. Pellegrini, Márcio M. Boniatti, Moreno C. Santos, Rodrigo Boldo, Vanessa M. Oliveira, Viviane M. Corrêa, Wagner Nedel; Hospital Moinhos de Vento, Porto Alegre-RS: Cassiano Teixeira, Roselaine P. Oliveira, Felipe Schaich, Luciana Tagliari, Augusto Savi, Luis F. Schulz, Juçara G. Maccari; UTI Central Irmandade Santa Casa de Misericórdia de Porto Alegre, Porto Alegre-RS: Roselaine P. Oliveira, Cassiano Teixeira, Gabriela M. Seeger, Rafael B. Foernges, Marcelo M. Rieder, Daniel A. Becker, Fabiano P. Broilo; UTI do Pavilhão Pereira Filho - Santa Casa de Misericórdia de Porto Alegre, Porto Alegre-RS: Patrícia Schwarz, André Alencastro, Paula Berto, Fabiane Backes, José A. S. Pellegrini; Hospital São Lucas da PUCRS, Porto Alegre-RS: Fernando S. Dias, Clarissa Blattner, Edna T. J. Martins, Nóris C. Scaglia; Hospital de Clínicas de Porto Alegre (HCPA), Porto 
Alegre-RS: Silvia R. R. Vieira, Karen F. Prado, Lea Fialkow, Cristiano Franke, Debora F. V. B. Vieira, Rafael B Moraes, Patrícia Schwarz, Leonardo S. Marques, João L. S. Hopf, Iuri C. Wawrzeniak, Tatiana H. Rech, Régis B. Albuquerque; Hospital Universitário São Francisco de Paula, Pelotas-RS: Márcio O. Guerreiro, Luciano O. Teixeira, Pedro L. Macedo, Marina P. Bainy, Edgard V. Ferreira; Hospital do Coração - Balneário de CamboriuSC: Marcio A. Martins, Luciana A. S. Andrade; Hospital Universitário - UFSC, Florianópolis-SC: Fernando O. Machado; Hospital Nereu Ramos, Florianópolis-SC: Ana C. Burigo, Mariangela Pincelli, Lara Kretzer, Israel S. Maia; Hospital UNIMED Joinville, Joinville-SC: Rodrigo B. Cordeiro, Glauco Westphal, Milton Caldeira, Amanda S. Cramer, Michelli M. Dadam, Pierry O. Barbosa; Hospital São José, Joinville-SC: Milton Caldeira, Glauco Westphal, Caroline O. Brilenger, Marina B. W. Horner, Glauce L. Oliveira, Bruno C. Germiniani, Cristina Teixeira, Robson Duarte; Hospital Regional Hans Dieter Schmidt, JoinvilleSC: Maria G. P. L. Assef, Deorgelis Rosso, Rodrigo Bigolin, Raquel Vanzuita; Associação Hospitalar e Maternidade Cônsul Carlos Renaux, Brusque-SC: Márcio A. Martins; Hospital Primavera, Aracaju-SE: Luiz F. A. Prado, André L. V. Oliveira, Diego L. Reis, Mirene O. Morais, Rafael S. Bastos, Hericalizandra S. R. Santana, Alline O. Silva, Lucas A. P. Cacau, Marília S. Almeida; Hospital de Urgência de Sergipe - HUSE, Aracaju-SE: Hugo Schlebinger Canavessi, Eduardo E. F. Nogueira, Caio L. P. Pavia, Diego L. Reis, José F. Araujo, José A. Lira, Esteban C. Nienstedt, Thiago C. Smith; Hospital do Coração - HCor, São Paulo-SP: Edson Romano, Marcelo Romano; Marisa M. Regenga, Dalton Barros, André F. Costa, Luzia Takahashi, Vinicius Werneck, Jorge Farran, Lilian A. Henriques, Claudia Miura; UTI da Clínica Médica - Hospital São Paulo UNIFESP, São Paulo-SP: Renato D. Lopes, Letícia S. Vendrame, Hélio P. Guimarães, Priscila Sandri, Marcela S. Galassi; UTI Respiratória - Hospital das Clínicas da FMUSP, São Paulo-SP: Carlos R. R. Carvalho, Marcelo B. P. Amato, Carlos Toufen Jr, Roberta R. S. Santiago, Adriana S. Hirota; UTI Clínica - Hospital das Clínicas da FMUSP, São Paulo-SP: Marcelo Park, Luciano C. P. Azevedo; UAC I e UAC II - Hospital das Clínicas da FMUSP, São Paulo-SP: Luiz M. Malbouison; UTI da Nefrologia - Hospital das Clínicas da FMUSP, São Paulo-SP: Maristela C. Costa; UTI Clínica do Pronto Socorro - Hospital das Clínicas da FMUSP, São Paulo-SP: Leandro Taniguchi; UTI Cirúrgica - Hospital das Clínicas da FMUSP, São Paulo-SP: Carlos E. Pompílio; Hospital Moyses Deutsch (M'Boi Mirim), São Paulo-SP: Claudio Baruzzi, Ana H. V. Andrade, Elisabete E. Taira, Bruno Taino, Clezio S. Oliveira, Anselmo C. Silva; Hospital do Servidor Público Estadual, São Paulo-SP: Alexandre Ísola, Ederlon Rezende, Ricardo G. Rodrigues, Vivian P. L. Rangel, Sergio Luzzi, Ivens W. S.Giacomassi; Hospital e
Maternidade São Camilo - Unidade Pompeia, São PauloSP: Antonio P. Nassar Jr, Ana R. Souza; Hospital São Luiz Unidade Itaim, São Paulo-SP: Luciana Rahal, Andre L. Nunes, Fabio Giannini, Brena Menescal, Jussara E. P. Morais, Diogo Toledo; Hospital São Luiz - Unidade Anália Franco, São Paulo-SP: Rafaela D. Morsch, Thalita Merluzzi, Denise S. Amorim, Ana C. A. G. Bastos, Patrícia L. Santos, Sabrina F. Silva, Raquel C. N. Gallego, Gheisa D. Santos; AC Camargo, São Paulo-SP: Mauro Tucci, Ramon T. Costa, Lucio S. Santos, Sergio E. Demarzo; Hospital Sírio Libanês, São Paulo-SP: Guilherme P. P. Schettino, Luciano C. P. Azevedo, Vivian C. Suzuki, Ana C. L. Patrocinio, Mariana L. Martins, Denise B. V. G. Passos; Hospital da Luz, São Paulo-SP: Sylas B. Cappi; Hospital SãoLuiz - Unidade Morumbi, São Paulo-SP: Iran Gonçalves Jr; HCRP-FMRP-USP, Ribeirão Preto-SP: Marcos C. Borges, Wilson Lovato, Marcel V. Tavares, Daniela Morales, Luis A. M. W. Machado, Franciele C. C. Torres, Tania M. Gomes, Rodrigo B. Cerantola; UTI do Pronto Socorro - Hospital São Paulo - UNIFESP, São Paulo-SP: Aécio Góis, Thiago Marraccini; Kathia Margarida, Eulália Cavalcante; UTI Anestesiologia Hospital São Paulo -UNIFESP, São Paulo-SP: Flávia R. Machado, Bruno F. Mazza, Heloisa B. Rossetti Santana, Vanessa M. F. Mendez, Patricia A. Xavier, Melina V. Rabelo, Fabiana R. Schievano, Walkyria A. M. Pinto, Renata S. Francisco, Elaine M. Ferreira; Instituto de Oncologia Pediátrica GRAACC - UNIFESP, São Paulo-SP: Dafne C. B. Silva, Rodrigo G. Arduini; Hospital e Maternidade São Cristóvão, São Paulo-SP: José R. Aldrighi, Andreson F. Amaro; Hospital José Soares Hungria, São Paulo-SP: Katia A. P. Conde; Hospital Municipal Professor Doutor Alipio Correa Neto, São Paulo-SP: Cesar A. Pereira, Elcio Tarkieltaub, Wilson R. Oliver, Erika G. L. Guadalupe, Paulo S. C. Acerbi, Carlos I. Tomizuka, Tatiana A. Oliveira, Nadia N. Geha; Hospital Universitário São Francisco, Bragança Paulista-SP: Giovana C. Mecatti, Maysa Z. R. Piovesan, Maria C. Salomão; Hospital UNIMED Araçatuba-SP: Marcelo S. Moreno, Vinicius N. Orsatti, Whiniton Miranda; Hospital Bandeirantes, São Paulo-SP: Alexandre Ray, André Guerra, Mario L. A. Baptista Filho; Hospital Geral São Mateus Dr. Manoel Bifulco, São Paulo-SP: Firmino H. Ferreira Jr, Edésio Viera Filho, Regina A. Canzi, Adriana F. T. Giuberti, Melissa C. M. Garcez; Hospital Escola Padre A. Pedro, Andrea D. Sala, Edmundo O. Suguitani, Priscila Kazue, Luiz R. C. Oliveira, Rodrigo M. Infantini; Instituto de Infectologia Emílio Ribas, São Paulo, SP: Fabrício R. T. Carvalho, Lucia C. Andrade, Hélio P. Guimarães; Hospital de Clínicas da UNICAMP, Campinas-SP: Thiago M. Santos, César V. Carmona, Luciana C. Figueiredo, Antonio Falcão, Desanka Dragosavak; Hospital das Clínicas Luzia de Pinho e Melo SPDM, Mogi das Cruzes-SP: Wilson Nogueira Filho, Maria C. Lunardi, Roberto Lago, Ciro Gatti, Tatiana M. 
Chiasso, Grazielle O. Santos, Aline C. F. Silva, Arthur C. Araujo; Irmandade Santa Casa de Misericórdia de Mogi Guaçu, Mogi Guaçu - SP: Izadora B. Ornellas, Vitor M. Vieira; Instituto do Câncer do Estado de São Paulo ICESP, São Paulo-SP: Ludhmila A. Hajjar, Adelaide C. Figueiredo; Hospital Maternidade UNIMED Leste Paulista, São João da Boa Vista-SP: Vitor M. Vieira, Bruna Damasceno. Colombia: Fundación Cardiovascular de Colombia, Bucaramanga: Camilo Pizarro; Los Comuneros Hospital Universitario de Bucaramanga, Bucaramanga: Alfredo Hinestrosa; Organización Latinoamericana para el Fomento de la Investigación en Salud - OLFIS, Bucaramanga: Fredi A. Diaz-Quijano. Mexico: Medica Sur, Ciudad de México-DF: Sandra M. C. García L., Octavio González C., Edgard Díaz S. Italy: Azienda Ospedaliera Universitaria P. Giaccone, Palermo: Santi M. Raineri, Andrea Cortegiani.

\section{Competing interests}

The authors declare that they have no competing interests.

\section{Authors' contributions}

$A B C, E A S, O B, M B P A$, and $C R R C$ conceived the study, participated in its design and coordination, and helped to draft the manuscript. FST, EACR, JMMT, ER, HPG, MMR, LNT, CT, RPO, VOC, and FADQ participated in the study design and helped to draft the manuscript. All authors read and approved the final manuscript.

\section{Acknowledgements}

The authors thank Maureen O Meade, MD, MSc (Department of Medicine, Clinical Epidemiology and Biostatistics, McMaster University, Hamilton, ON, Canada) and the clinical team of the Respiratory ICU. Hospital das Clínicas, Faculdade de Medicina (University of São Paulo, São Paulo, SP, Brazil) for their very significant contribution on protocol design.

\section{Sources of funding}

This study is funded by the Hospital do Coração (HCor) as part of the Program 'Hospitais de Excelência a Serviço do SUS (PROADI-SUS)' in partnership with the Brazilian Ministry of Health.

\section{Author details}

Research Institute - Hospital do Coração (IEP- HCor), Rua Abílio Soares 250, 12th floor, CEP: 04005-000, São Paulo, SP, Brazil.

Received: 23 February 2012 Accepted: 5 July 2012

Published: 28 August 2012

\section{References}

1. Esteban A, Anzueto A, Frutos F, Alia I, Brochard L, Stewart TE, Benito S, Epstein SK, Apezteguia C, Nightingale P, Arroliga AC, Tobin MJ: Characteristics and outcomes in adult patients receiving mechanical ventilation: a 28-day international study. JAMA 2002, 287:345-355.

2. Rubenfeld GD, Caldwell E, Peabody E, Weaver J, Martin DP, Neff M, Stern EJ, Hudson LD: Incidence and outcomes of acute lung injury. N Engl J Med 2005, 353:1685-1693.

3. Phua J, Badia JR, Adhikari NK, Friedrich JO, Fowler RA, Singh JM, Scales DC, Stather DR, Li A, Jones A, Gattas DJ, Hallett D, Tomlinson G, Stewart TE, Ferguson ND: Has mortality from acute respiratory distress syndrome decreased over time?: A systematic review. Am J Respir Crit Care Med 2009, 179:220-227.

4. Herridge MS, Cheung AM, Tansey CM, Matte-Martyn A, Diaz-Granados N, Al-Saidi F, Cooper AB, Guest CB, Mazer CD, Mehta S, Stewart TE, Barr A, Cook D, Slutsky AS: One-year outcomes in survivors of the acute respiratory distress syndrome. N Engl J Med 2003, 348:683-693.

5. Herridge MS, Tansey CM, Matte A, Tomlinson G, Diaz-Granados N, Cooper A, Guest CB, Mazer CD, Mehta S, Stewart TE, Kudlow P, Cook D, Slutsky AS,
Cheung AM: Functional disability 5 years after acute respiratory distress syndrome. N Engl J Med 2011, 364:1293-1304.

6. International consensus conferences in intensive care medicine: Ventilatorassociated lung injury in ARDS. Am J Respir Crit Care Med 1999, 160:2118-2124.

7. Gattinoni L, Protti A, Caironi P, Carlesso E: Ventilator-induced lung injury: the anatomical and physiological framework. Crit Care Med 2010, 38:S539-S548.

8. Chiumello D, Pristine G, Slutsky AS: Mechanical ventilation affects local and systemic cytokines in an animal model of acute respiratory distress syndrome. Am J Respir Crit Care Med 1999, 160:109-116.

9. Grasso S, Stripoli T, De MM, Bruno F, Moschetta M, Angelelli G, Munno I, Ruggiero V, Anaclerio R, Cafarelli A, Driessen B, Fiore T: ARDSnet ventilatory protocol and alveolar hyperinflation: role of positive end-expiratory pressure. Am J Respir Crit Care Med 2007, 176:761-767.

10. Muscedere JG, Mullen JB, Gan K, Slutsky AS: Tidal ventilation at low airway pressures can augment lung injury. Am J Respir Crit Care Med 1994 149:1327-1334.

11. Tremblay L, Valenza F, Ribeiro SP, Li J, Slutsky AS: Injurious ventilatory strategies increase cytokines and c-fos m-RNA expression in an isolated rat lung model. J Clin Invest 1997, 99:944-952.

12. Villar J, Kacmarek RM, Perez-Mendez L, Aguirre-Jaime A: A high positive end-expiratory pressure, low tidal volume ventilatory strategy improves outcome in persistent acute respiratory distress syndrome: a randomized, controlled trial. Crit Care Med 2006, 34:1311-1318.

13. Borges JB, Okamoto VN, Matos GF, Caramez MP, Arantes PR, Barros F, Souza CE, Victorino JA, Kacmarek RM, Barbas CS, Carvalho CR, Amato MB: Reversibility of lung collapse and hypoxemia in early acute respiratory distress syndrome. Am J Respir Crit Care Med 2006, 174:268-278.

14. de Matos GF, Stanzani F, Passos RH, Fontana MF, Albaladejo R, Caserta RE, Santos DC, Borges JB, Amato MB, Barbas CS: How large is the lung recruitability in early acute respiratory distress syndrome: a prospective case series of patients monitored by computed tomography. Crit Care 2012, 16:R4

15. Fan E, Wilcox ME, Brower RG, Stewart TE, Mehta S, Lapinsky SE, Meade MO, Ferguson ND: Recruitment maneuvers for acute lung injury: a systematic review. Am J Respir Crit Care Med 2008, 178:1156-1163.

16. Hodgson CL, Tuxen DV, Davies AR, Bailey MJ, Higgins AM, Holland AE, Keating JL, Pilcher DV, Westbrook AJ, Cooper DJ, Nichol AD: A randomised controlled trial of an open lung strategy with staircase recruitment, titrated PEEP and targeted low airway pressures in patients with acute respiratory distress syndrome. Crit Care 2011, 15:R133.

17. Bernard GR, Artigas A, Brigham KL, Carlet J, Falke K, Hudson L, Lamy M, Legall JR, Morris A, Spragg R: The American-European Consensus Conference on ARDS. Definitions, mechanisms, relevant outcomes, and clinical trial coordination. Am J Respir Crit Care Med 1994, 149:818-824.

18. Brower RG, Lanken PN, Maclntyre N, Matthay MA, Morris A, Ancukiewicz M, Schoenfeld D, Thompson BT: Higher versus lower positive end-expiratory pressures in patients with the acute respiratory distress syndrome. $\mathrm{N}$ Engl J Med 2004, 351:327-336.

19. Montori VM, Devereaux PJ, Adhikari NK, Burns KE, Eggert CH, Briel M, Lacchetti C, Leung TW, Darling E, Bryant DM, Bucher HC, Schunemann HJ, Meade MO, Cook DJ, Erwin PJ, Sood A, Sood R, Lo B, Thompson CA, Zhou $Q$, Mills $E$, Guyatt GH: Randomized trials stopped early for benefit: a systematic review. JAMA 2005, 294:2203-2209.

20. Mueller PS, Montori VM, Bassler D, Koenig BA, Guyatt GH: Ethical issues in stopping randomized trials early because of apparent benefit. Ann Intern Med 2007, 146:878-881.

\section{doi:10.1186/1745-6215-13-153}

Cite this article as: The ART Investigators: Rationale, study design, and analysis plan of the Alveolar Recruitment for ARDS Trial (ART): Study protocol for a randomized controlled trial. Trials 2012 13:153. 